\title{
Household-Level Consumption in Urban Ethiopia: \\ The Effects of a Large Food Price Shock
}

\author{
Yonas Alem ${ }^{\dagger}$ and Måns Söderbom
}

March 2011

\footnotetext{
${ }^{\dagger}$ Department of Economics, University of Gothenburg, Sweden; School of Economics, Addis Ababa University, Ethiopia. E-mail: Yonas.Alem@economics.gu.se.

${ }^{\ddagger}$ Department of Economics, University of Gothenburg, Sweden. E-mail:

Mans.Soderbom@economics.gu.se.
} 


\section{Summary of the paper}

We use survey data to investigate how urban households in Ethiopia coped with the food price shock in 2008. Qualitative data indicate that the high food price inflation was by far the most adverse economic shock between 2004 and 2008, and that a significant proportion of households had to adjust food consumption in response. Regression results indicate that households with low asset levels, and casual workers, were particularly adversely affected by high food prices. We interpret the results as pointing to the importance of growth in the formal sector so as to generate more well-paid and stable jobs.

JEL classification: O12, O18, D12.

Keywords: consumption, welfare, food price shock; Africa, urban Ethiopia. 


\section{Acknowledgements}

We would like to thank three anonymous referees, Arne Bigsten, Tessa Bold, Paul Collier, Stefan Dercon, Dick Durevall, Marie Gachassin, Gunnar Köhlin, Lennart Hjalmarsson, Francis Teal and seminar participants at the University of Gothenburg, the University of Örebro, participants at the CSAE conference "Economic Development in Africa”, Oxford, March 21-23, 2010, and participants the Development Economics Workshop at Säröhus, Gothenburg, Oct 1-2, 2009 for very useful comments on earlier versions of the paper. The 2008/09 household survey was funded by Sida through the Environmental Economics Unit (EEU) of the Department of Economics, University of Gothenburg. Söderbom gratefully acknowledges financial support from Sida/Sarec. The views expressed in this paper are entirely those of the authors. 


\section{INTRODUCTION}

In February 2011, the Food and Agricultural Organization of the United Nations (FAO) Food Price Index (FFPI) rose for the eighth consecutive month, to the highest level since January 1990, the date at which the index was first computed. Soaring food prices have become a major concern amongst policy makers. For example, the group of 20 developed and leading emerging economies (G20) have put the food price spike and food security at the top of their 2011 agenda. Food prices soared previously in 2008. In this paper we investigate the effects of the 2008 food price shock on what would seem likely a very exposed population, namely urban households in Ethiopia. In July 2008 food prices in Ethiopia had increased to an unprecedented level, on average 92 percent higher than twelve months earlier. Food prices then began to fall, and during the first six months of 2009 they stabilized at a level about 15 percent lower than at the peak in 2008, on average (Central Statistics Agency, 2008, 2009). These dramatic developments are illustrated in Figure 1.

(Figure 1 here)

There are several reasons the effects on food consumption, and welfare more generally, may have been quite serious, at least for certain types of households in urban Ethiopia. ${ }^{1}$ First, the share of household expenditure spent on food in urban Ethiopia is high, suggesting that welfare is sensitive to food price changes. Second, little food production takes place in urban areas, thus higher food prices do not raise urban incomes. Urban households are not in a good position to produce for own consumption, another notable difference compared to rural households. Third, there is no formal insurance mechanism for this type of shock. 
These and other related factors suggest the welfare effects of higher food prices would vary considerably across urban households. One reason is that there is likely substantial heterogeneity across households in the ability to cope with shocks. Standard intertemporal models of consumption predict a small effect of a transitory price shock on utility if, as seems likely, households desire a stable consumption path and are able to smooth consumption over time, e.g. by borrowing or by tapping into financial assets accumulated in the past. Since not all households in urban Ethiopia are in a position to smooth consumption intertemporally, some may be more vulnerable than others. In particular, it seems likely that poor households may be unable to self-insure since they possess low levels of financial assets. Another reason why the welfare effects may vary across households is heterogeneity in consumption patterns. For example, in our sample it is clear that poor households spend a larger share of their food budget on cereals, compared to households that are better off. As will be shown below, cereals one of the items within the food basket for which inflation was particularly high. Hence, it seems likely that poor households fared particularly badly during the period of high food prices. Furthermore, it seems quite likely that the effect of the food price shock may vary depending on labor market status. For example, casual urban workers may be quite exposed to a food price shock if this impacts strongly on local demand. As will be discussed below, there are other reasons too to suppose that labor market status matters in this context. We therefore pay close attention to the occupational status of the household head and the members of the household in the empirical analysis.

The main goal of the paper is to establish what types of households were most adversely affected by the 2008 food price shock. To this end we use panel data on urban households in Ethiopia for 2008, 2004 and 2000. Our empirical approach consists of three different, but related, methods. First, we carry out a conventional before-after analysis, modeling the change 
in log consumption between 2004 and 2008 as a function of a set of household variables. This will tell us if and how changes in consumption varied across certain types of households over this period. A similar approach has been used by Glewwe and Hall (1998) in their analysis of the effects of the macroeconomic decline in Peru in the late 1980s on household welfare. Second, we undertake a dynamic comparison of consumption growth rates and their determinants, contrasting the shock period (2004-2008) to a baseline period (2000-2004). One attractive feature of using data from 2000-2004 to form a baseline is that price inflation over this period was low. Third, we investigate how self-reported effects of the food price shock on food consumption vary across households, using data from the most recent survey.

Overall, we find that the dynamic comparison and the analysis of self-reported effects yield results that are qualitatively similar, with slightly better statistical significance for those based on the self-reported data. We find that households with low levels of assets, and households headed by a casual worker, were particularly adversely affected by the food price inflation. In contrast, the results suggest that education has played at most a small role for the ability of households to cope with food price inflation. Similarly, household demographics appear to play a limited role in this context. We also consider the effects of idiosyncratic shocks such as the death or illness of a family member, the loss of assets, or unemployment. We find that a job loss has a large negative effect on consumption growth, suggesting that households are unable to insure themselves against this type of shock.

Some implications for policy follow from our results. For example, our finding that workers whose skills are in low or volatile demand are very exposed points to the importance of facilitating for the creation of more relatively well-paid and stable jobs in urban Ethiopia. Policies facilitating for growth of stable jobs may thus improve the ability of the urban 
population to cope with shocks. Our research also has implications for how to design effective policies in periods of high food prices. During the food price crisis in 2008, the Ethiopian government undertook to help urban households by providing low cost wheat. Since no explicit targeting of households was adopted, the allocation of the resources devoted to the support program may have been inefficient. For example, poor households had no better access to cheap wheat than relatively well-off households and therefore received less support than might have been possible with a well targeted program. With knowledge about which groups are least able to cope with shocks, better and more effective policies can be formulated.

The remainder of the paper is organized as follows. Section 2 provides background information on the performance of the Ethiopian economy, food prices and general inflation. Section 3 reviews previous research and discusses theoretical predictions on the relationship between price shocks and consumption. Section 4 describes our empirical approach. Section 5 describes the data source and contains descriptive statistics. Section 6 contains the results from our econometric analysis. Section 7 provides conclusions.

\section{ECONOMIC PERFORMANCE, INFLATION AND FOOD PRICES IN ETHIOPIA}

Ethiopia is one of the poorest countries in the world. The economy is predominantly agrarian; in the year 2009, for instance, about 43 percent of the GDP, 60 percent of exports, and 85 percent of total employment was generated from this sector (Central Intelligence Agency, 2009). Poverty is a serious development problem for the country and in the year 2005 about 38 percent of the population lived below the official poverty line. Bigsten and Shimeles (2008) document evidence indicating that shocks play an important role in moving people in and out of poverty. Beginning 2002, the Ethiopian government has adopted a development 
strategy called “Sustainable Development and Poverty Reduction Program (SDPRP)” centered on the principal goal of reducing poverty in the country. Official statistics indicate that Ethiopia's economy has grown rapidly during the last five years. Table A.1 in the Appendix shows some macroeconomic indicators. According to Table A.1, real GDP on average grew by about 11 percent during the years 2004 to 2008. During the same period, however, the country exhibited the highest rate of inflation in its history and the highest in the world next to Zimbabwe in 2008 (Central Intelligence Agency, 2009). Overall inflation rose from 15 percent in June 2007 to 55 percent in June 2008 (Loening et al. 2009). ${ }^{2}$

The driving factors behind the high general inflation rate in Ethiopia have been extensively discussed. The World Bank (2007) and the IMF (2008) argue that excess aggregate demand generated by expansionary monetary policy were key driving factors of overall inflation, calling for forceful policy tightening. EDRI (2007) and FAO (2008a) however highlight a multitude of domestic and external factors that could account for the inflation, among them (i) increase in international commodity prices including oil; (ii) structural change and continued good economic performance; (iii) increasing supply of money and injection of cash into the rural economy; (v) changes in farmers' behavior to supply products more uniformly over the year (improvements in access to micro-credit, storage facilities, marketing information, etc; and (vi) increased local purchases by governmental food security institutions, agricultural cooperatives, and relief agencies. More recently, Loening et al (2009) have argued that in the short to medium run, agricultural supply shocks and inflation inertia strongly affect domestic inflation in Ethiopia, causing large deviations from long-run price trends.

Global food prices have been increasing rapidly since 2005. International food prices in April 2008 were 60 percent higher than 12 months earlier. There is some evidence indicating that 
world food prices have been driven by higher grain prices. For instance the international price of wheat more than tripled between 2002 and March 2008. The price has since then come down, but as of August 2008 it remained 70 percent higher than the average price in 2006 . Similar trends have been exhibited for other cereals and food items (Ahmed, 2008; Ivanic and Martin, 2008). Several factors have been mentioned as causes of the surge in global food prices in 2008, for example: rising population; rapid economic growth in emerging economies which resulted in increased food demand; high energy and fertilizer prices; increased use of food crops for bio-fuels; depreciation of the US dollar; and declining global stocks of food grains due to changes to buffer stock policies in the US and European Union (Ahmed, 2008). FAO (2008b) argue that the use of agricultural products, in particular maize, wheat and vegetable oil, as feedstock for biofuel production has been the most important factor behind the rise of global food prices during 2005-2008. More recently, Gilbert (2009) has argued that the world food price hikes in 2006-2008 are mainly explained by depreciation of dollar and future market investments.

\section{SHOCKS AND CONSUMPTION}

The impact of shocks on individual welfare in poor countries is a research topic that has attracted a lot of interest from academics and policy makers. ${ }^{3}$ Most studies have focused on income shocks. The theoretical model underlying such studies typically has the individual choosing consumption so as to maximize the present discounted value of current and (expected) future utility, subject to a set of relevant constraints. (see e.g. Fafchamps, 2003, for a thorough discussion of how this type of framework has been used in development economics). The utility function is typically specified as strictly concave in consumption, which implies that the individual dislikes consumption volatility. Consequently, the individual will seek to offset the effects of income shocks on consumption, for example by adjusting the 
level of assets. Under this type of behavior, often referred to as consumption smoothing in the literature, the impact of temporary income shocks on consumption will be small, a prediction that many empirical studies set out to test (e.g. Paxson, 1992; Udry, 1995). ${ }^{4}$ While insurance and credit markets are usually poorly developed in poor countries, households can still protect themselves against temporary income shocks by building up a sufficient buffer stock that they can tap into in difficult times. Empirical evidence that assets are accumulated in this manner has been reported by e.g. Behrman et al. (1997), Lim and Townsend (1998), and Rosenzweig and Wolpin (1993). ${ }^{5}$ Nevertheless, the empirical literature for developing countries, which primarily is concerned with rural households, typically provides evidence that income shocks tend to affect welfare suggesting limited ability of in particular poor households to cope with such shocks (e.g. Townsend, 1994; Dercon, 2004; Skoufias and Quisumbing, 2005).

The dynamic implications of price shocks have received less attention in the microeconomic development literature. A temporary price shock will have a temporary income effect but also a substitution effect. For example, if the price this period is high relative to what is expected in the next period, it may be optimal for the individual to consume relatively less this period than in the next period. Hence, while a temporary income shock may have a small effect on consumption, the effect of a temporary price shock may be large. To illustrate this, suppose the utility function $\mathrm{U}$ exhibits constant relative risk aversion,

$$
U\left(C_{t}\right)=\left\{\begin{array}{l}
C_{t}^{1-\sigma} /(1-\sigma) \text { for } \sigma>0, \sigma \neq 1 \\
\ln C_{t} \text { for } \sigma=1
\end{array}\right\},
$$

where $C_{t}$ denotes consumption in period $t$ and $\sigma$ is a parameter. Denote the discount rate in the intertemporal utility maximization problem by $r$ and assume this is constant. Consider first the case where individuals can borrow and save at the constant rate $r$, i.e. a perfect capital markets scenario. Optimal consumption in period $t$ is then such that 


$$
\frac{C_{t}^{-\sigma}}{P_{t}}=E_{t}\left(\frac{C_{t+1}^{-\sigma}}{P_{t+1}}\right)
$$

where $P_{t}$ denotes the price of consumption. Abstracting from uncertainty (in order to highlight the intertemporal substitution mechanism) this can be written as

(1) $\frac{C_{t}}{C_{t+1}}=\left(\frac{P_{t+1}}{P_{t}}\right)^{1 / \sigma}$

This shows that if the price in period $t$ is high relative to that in period $t+1$, consumption in period $t$ will be lower than in period $t+1$. Just how much lower is determined by the parameter $\sigma$ : the higher the value of $\sigma$, the lower is the effect of a given relative price difference on the relative difference in consumption across the two periods. For the model with $\sigma=1$, so that utility is logarithmic in consumption, there is a negative 1:1 relationship between the relative price and relative consumption; for higher values of $\sigma$, the effect on consumption is smaller. Given that our focus is on food consumption, it is reasonable to suppose that $\sigma$ is rather high, reflecting limited willingness to substitute food consumption across time periods.

Now suppose individuals cannot borrow. Consider an individual with no accumulated assets who is exposed to a temporary price increase in period $t$. For simplicity, suppose the price is expected (with probability 1) to revert to its normal level in the next period. Since $\sigma$ is high, desired consumption in period $t$ is close to the normal level (see eq. 1). However because the individual has no assets and cannot borrow, consumption expenditure in period $t$ cannot exceed the level of income generated in period $t$. This implies that, holding income constant, the relative decrease in consumption must be equal to the relative increase in the price so as to keep expenditure constant. In other words, even though $\sigma$ is high, consumption may be quite sensitive to a price increase for individuals who lack the means to smooth consumption over time. Heterogeneity in the effect of a food price shock may thus reflect heterogeneity across individuals in the ability to cope with the shock. 
Next consider a framework in which utility is explicitly defined as dependent on a vector of different food items (as well as other goods). If preferences are homothetic and all individuals face the same prices, the consumption ratio for any two goods is constant across rich and poor individuals at a given point in time. This is typically not what one would observe in real data however. Poor individuals (households) typically spend a relatively large share of their food budget on inexpensive products, while more well-off individuals tend to spend a larger share of their budget on 'luxury' products. As we shall see below, households in our sample with low levels of assets spend a larger share of their total food expenditure on items like cereals, pulses, spices, and coffee and tea, and a smaller share on meat, dairy products and oils and fats, than do wealthier households. This suggests preferences are in fact non-homothetic. This, in turn, suggests that the impact of a food price shock may differ across households of differing economic status. For example, poor households may be severely affected if prices increase most for the products intensively consumed by the poor. In this example, assets may thus correlate with the size of the food price shock even if assets play no role for consumption smoothing. If assets matter for the ability to smooth consumption as well, this would compound the heterogeneity in the effect of the food price across rich and poor households.

Finally, the effect of the food price shock may vary depending on labor market status. Workers whose nominal salaries are fixed in the short term - e.g. public sector employees will obviously see a strong reduction in the real wage as a result of high food prices and may therefore be more severely affected than individuals whose nominal incomes rise with inflation. Individuals whose incomes are dependent on demand in the local urban market may also be quite exposed, since local demand in urban areas likely falls rather strongly as a result of the food price shock (more so than in rural areas, for example, where high food prices may 
have a positive income effect, or in international markets where food prices rose less dramatically). This effect would be amplified for workers whose foothold in the labor market is weak. This suggests casual urban workers may be particularly exposed to a food price shock.

Summarizing, we have discussed several potential reasons why a large food price shock may impact differently across different types of households. We have identified two possible reasons why the effect may be stronger for individuals or households with low levels of assets (limited ability to smooth consumption and strong preferences towards food items for which prices were rapidly increasing), and we have noted that labor market status may be a source of heterogeneity in the effect too. Next, we outline our empirical framework used to study these and other related effects.

\section{EMPIRICAL APPROACH}

Our main aim in this paper is to document the effects of the 2008 food price shock across households in urban Ethiopia, and to shed light on whether certain types of households are relatively 'vulnerable' to food price shocks. ${ }^{6}$ We focus on three household level outcomes: household consumption of food, measured as food expenditure per adult equivalent (henceforth, food consumption); the overall effect of the food price shock as perceived by the household head; and a self-reported measure of the effect of the shock on the quantity of food consumed. $^{7}$ We define $\Omega_{i j}$ as the effect of the food price shock on expected outcome $j$ for household $i$. We let period $T$ denote the shock period, and model the effect of the shock using a simple linear specification

$$
\Omega_{i j}=\gamma_{j 0}+\mathbf{X}_{i, T-1} \boldsymbol{\gamma}_{J}^{1}+\Delta \mathbf{X}_{i T} \boldsymbol{\gamma}_{J}^{2},
$$


where $\gamma_{j 0}$ is an intercept, $\mathbf{X}_{i, T-1}$ is a vector of observable household characteristics, $\Delta \mathbf{X}_{i t}$ is a vector of explanatory variables expressed in first differences, and $\boldsymbol{\gamma}_{J}^{1}, \boldsymbol{\gamma}_{J}^{2}$ are parameter vectors. Hence, if the ability to cope with the food price shock depends on household characteristics or changes in those characteristics, some elements of the vectors $\gamma_{J}^{1}, \gamma_{J}^{2}$ will differ from zero. In the empirical analysis we include the following variables in the vector $\boldsymbol{X}$ : household assets; the age, education, occupation and sex of the household head; the number of adult household members, distinguishing between different occupations; the number of children (younger than 15) and elderly (older than 65) in the household; and location of the household. By controlling for the headcount for each occupation of the adult household members and the number of children and elderly, we control for household size while allowing for the possibility that the effect of household size may depend on the demographic composition and the occupations of the household members. The age, education and sex of the household head, and the location of the household, are not included in the vector of differenced explanatory variables.

\section{(a) Identification strategy}

In this sub-section we discuss the assumptions under which the parameters of interest $\left(\gamma_{J}^{1}, \gamma_{J}^{2}\right.$ ) can be identified. We specify our general model of food consumption as

$$
\ln C_{i t}=\mathbf{X}_{i t} \boldsymbol{\alpha}+\sum_{k=1}^{K} \theta_{k} \sum_{s=0}^{t-1} X_{i s}^{k}+\Omega_{i 1} S_{t}+\beta_{t}+\delta_{i}+\varepsilon_{i t}
$$

where $C_{i t}$ denotes food consumption, $\mathbf{X}_{i t}=\left(X_{i t}^{1}, \ldots, X_{i t}^{K}\right)$ is vector of determinants of food consumption, $\beta_{t}$ is a time effect, $\delta_{i}$ is a fixed effect capturing unobserved time invariant heterogeneity across households in consumption, $\varepsilon_{i t}$ is a residual assumed uncorrelated with 
all other terms on the right-hand sided of (3), while $\boldsymbol{\alpha}$ and $\boldsymbol{\theta}=\left(\theta_{1}, \ldots, \theta_{K}\right)$ are parameter vectors. $^{8}$ Taking first difference of (3) removes the household fixed effects:

$$
\Delta \ln C_{i t}=\Delta \mathbf{X}_{i t} \boldsymbol{\alpha}+\mathbf{X}_{i, t-1} \boldsymbol{\theta}+\left\{\gamma_{10}+\mathbf{X}_{i, t-1} \gamma_{1}^{1}+\Delta \mathbf{X}_{i t} \gamma_{1}^{2}\right\} S_{t}+\beta_{t}+\Delta \varepsilon_{i t}
$$

It is now straightforward to see that the vector $\boldsymbol{\theta}$ is interpretable as consumption growth effects. For example, if $\theta_{1}>0$, then a high value of $X_{i t}^{1}$ leads to high growth over the subsequent period. It follows that the level of consumption in period $t$ depends on the accumulation of the variable $X^{1}$ at that point, which is reflected in (3). It also follows that if $X^{1}$ is time invariant, the cumulative term becomes an interaction term between $X^{1}$ and time. It should be noted that, in a model in which the parameters vary freely over time, coefficients on time invariant explanatory variables in a first-differenced equation are interpretable as changes in the coefficients in the levels specification between periods (see e.g. Glewwe and Hall, 1998).

Given the specification in (4), we need at least three rounds of data in order to identify our parameters of interest $\left(\gamma_{10}, \gamma_{J}^{1}, \gamma_{J}^{2}\right)$. With just two waves of data, (4) would reduce to a beforeafter model, similar to that adopted by Glewwe and Hall (1998). Parameter estimates obtained from such a model would be informative about patterns of consumption changes between the two time periods. But they would not be interpretable as causal effects unless $\beta_{1}=0, \boldsymbol{\theta}=0$, $\boldsymbol{\alpha}=0$, i.e. expected consumption growth would have to be zero and independent of household characteristics in non-shock periods. This would be quite a restrictive assumption. With three waves of data available, two data points per household are available after taking first differences. In such a case (4) can be estimated using OLS and $\gamma_{10}, \gamma_{J}^{1}, \gamma_{J}^{2}$ (and hence $\Omega_{i 1}$ ) can be identified from the coefficients on the time dummy and the interaction terms $\mathbf{X}_{i, t-1} S_{t}$ and $\Delta \mathbf{X}_{i t} S_{t}$. 
As is emphasized in much of the recent treatment effects literature, identification of the causal effect of some treatment requires a counterfactual - the outcome in an alternative scenario in which individuals are not treated - to which actual outcomes can be compared. The most common way of constructing counterfactuals for treated individuals is to use data on similar individuals not exposed to the treatment. As already discussed, in our application the food price shock is common to all households at one point in time, hence no control group exists in the cross-section. The identification strategy described above amounts to letting households observed prior to the shock period, in our case 2000-2004, constitute the control group. The average inflation rate over the 2000-2004 period was lower than 4 percent on average, which stands in sharp contrast to the situation during 2004-2008. It could be, of course, that this still does not produce a valid counterfactual. Our identification strategy would not work, for example, if as is the case in the model proposed by Glewwe and Hall (1998) parameters vary freely across time periods. The analysis of our qualitative outcome variables ought to shed some light on whether this is a serious problem. We turn to the qualitative outcome variables next.

In the survey we asked the respondents how the food price shock affected the household's food consumption in general (distinguishing very negatively, negatively or not at all as possible answers) and whether the household cut back on the quantity of food consumed as a result of the food price shock (yes or no). Households were thus asked to assess the (qualitative) difference in consumption under treatment (the food price shock) compared to the counterfactual. We model these outcomes directly using ordered probit for the perceived general effect, and binary probit for the variable indicating whether the quantity of food consumed was affected. We note that these probit specifications can be derived from latent 
variable equations of the form $\widetilde{\Omega}_{i j}=\Omega_{i j}+\xi_{i j}, j=2,3$, where $\xi_{i j}$ is an error term with mean zero and variance equal to one, assumed normally distributed and uncorrelated with $\Omega_{i j}$. Because the underlying survey questions refer specifically to effects of the food price shock, the impact of confounding factors (e.g. high energy prices or economic growth) should be small in this modeling framework. This is potentially an important advantage compared to the analysis based on consumption data, where confoundedness may be an issue. However there may be problems too. Ravallion and Lokshin (2001) stress that, in general, measurement errors and differences in latent psychological factors across respondents may yield misleading results in the analysis of subjective-qualitative survey questions. Indeed, if different households have different reference points, answers to subjective questions may not be comparable across households. Moreover, because only a small number of outcomes are distinguished, our qualitative variables may not be very informative. Our belief is that there is value-added to comparing the results produced by the different methods. For example, if the results in the analysis of the qualitative variables are completely different from those from the consumption regressions this would suggest that something has gone awry, whereas if the results are similar this would provide some reassurance.

Throughout the empirical analysis we try to correct for various forms of omitted variables bias. The analysis of the food consumption expenditure data allows for unobserved household fixed effects, which, if ignored, might lead to omitted variables bias. We use data from survey questions that refer specifically to effects of the food price shock, which ought to lessen the impact of confounding factors (e.g. high energy price prices or economic growth). However we do assume that the explanatory variables are econometrically exogenous, i.e. uncorrelated with the residual part of the outcomes under study. This may be restrictive. For example, omitted factors, such as general ability or 'social capital', may impact on the effects of the 
food price shock. If such unobserved factors are correlated with the observed explanatory variables, our parameter estimates are not interpretable as causal effects but rather as partial correlations. The empirical analysis below should be viewed in this light.

\section{DATA AND DESCRIPTIVE STATISTICS}

Our empirical analysis is based on survey panel data for 2008, 2004 and 2000. The most recent survey, fielded by us in late 2008 and early 2009, covered 709 households located in Addis Ababa, Awassa, Dessie and Mekelle. One of the key objectives was to generate data suitable for analysis of the effects of the food price shock. We therefore included in the survey instrument several questions referring to the perceived effects of the food price shock. We also ensured the data could be linked with data for 2004 and 2000, enabling us to analyze consumption growth. The two earlier waves of data derive from the Ethiopian Urban Socioeconomic Survey (EUSS), organized by the Department of Economics at Addis Ababa University in collaboration with the University of Gothenburg in Sweden. ${ }^{9}$ Out of the 709 households surveyed in 2008/09, 128 are new households drawn randomly from the urban population for the first time in 2008/09. We surveyed these new households in order to investigate if the panel households - some of which were initially selected in 1994, see note 9 - have become atypical and not very well representative of the Ethiopian urban population. To form our estimation sample, we dropped 24 of the 581 panel households because information on these households was missing in the 2004 round. Our final sample based on the 2008/09 survey contains 557 households; 341 from Addis, 71 from Awassa, 70 from Dessie and 75 from Mekelle. Our dataset contains information on household living-conditions including income, expenditures, demographics, health, educational status, occupation, productionactivities, asset ownership and other variables. In addition, new modules on shocks and coping mechanisms were included in the 2008/09 survey instrument. 
We first consider descriptive statistics for variables measuring shocks and coping mechanisms. Table 1 provides information on the incidence of shocks in urban Ethiopia during 2004-2008 based on self-reported data obtained in the most recent survey. By far the most common shocks refer to the rapid increase in food prices (94 percent) and rising energy prices (74 percent). ${ }^{10}$ The most commonly cited idiosyncratic shock is death of a household member (non-spouse) (9 percent), followed by serious illness of wife (6 percent). When asked to indicate the most influential shock (idiosyncratic or covariate) during 2004-2008, 89 percent of the households considered the food price shock as the main shock, which completely dwarves the other types of shocks. A follow-up question on households' expectation of the re-occurrence of the most influential shock was also asked and 74 percent of the households responded that they thought the risk of such a shock happening again had increased.

(Table 1 here)

There has been a lot of evidence documented in the literature on shocks and coping mechanisms that households faced by uninsured risk and shocks adopt their own coping mechanisms to protect themselves against a serious decline in welfare. In view of this, the households interviewed in the 2008/09 survey were asked about the coping strategies they adopted in response to the food price shock. Table 2 presents these data. The four leading coping mechanisms are as follows: 36 percent of the households reported that they cut back on the quantities served per meal; 20 percent received assistance from relatives and friends both from domestic and foreign sources; 16 percent coped by shifting resources from other consumption items to food; and 9 percent of the households earned extra income from 
activities such as increased labor force participation or renting out residential houses. Intriguingly, only 6 percent of the households seemed to use own assets or loans to cope with the shock. This suggests that consumption smoothing through borrowing is not common in urban Ethiopia.

(Table 2 here)

The data thus suggest the food price shock has been a major adverse economic event in urban Ethiopia, affecting the consumption and, presumably, the welfare of a significant number of households. In the next section we discuss our econometric results on the heterogeneous effects of the food price shock. Table 3 shows summary statistics for the key variables in the regression analysis, across the three years considered. Since households that were sampled for the first time in 2008/09 cannot be included in consumption growth equations, these are excluded from our estimation sample. All financial variables are expressed in real terms using 1994 as the base year. For food consumption per adult equivalent, we observe a modest increase in the sample average over time. In 2008 the sample average of log overall consumption is 4.78 which corresponds to 119 birr per month expressed in constant 1994 values. The share of food expenditure in total expenditure is 0.78 , suggesting a high sensitivity of welfare to food price changes. Related to this, 60 percent of the households interviewed in 2008/09 say that food consumption has been very negatively affected by the food price shock; a further 29 percent say that the effect has been negative, leaving 11 percent stating that there had been no effect. Thirty-two percent of the households in the estimation sample state that they have cut back on the quantity of food served in response to the food price shock. ${ }^{11}$ About half of the household heads are female, and the average age of the head is 55 in the last wave of the data. In 2008 the sample average of household size, excluding the household head, is 
5.39. This is lower than in 2000, reflecting a natural process by which children exit from the household as they become older. Consistent with this, the average number of children in the household falls from 1.90 in the 2000 sample to 1.03 in the 2008 sample. Education is low on average, and around 40 percent of the household heads have no education. Slightly less than half of the households own their own house, and the average log real value of household assets ranges between 6.86 in 2000 (which corresponds to 953 Birr) and 7.29 in 2008 (1,466 Birr). ${ }^{12}$ The most common type of occupation for household heads that are in the labor force is to be self-employed, followed by public sector employee (including civil servants). However, between 41 and 45 percent of the heads are out of the labor force, a category that includes housewives, retired individuals and other individuals not actively seeking work.

(Table 3 here)

\section{ECONOMETRIC ANALYSIS}

(a) Consumption levels

We begin by reporting results from regressions in which log consumption per adult equivalent in 2008 is the dependent variable, distinguishing food consumption and overall (all types of) consumption. By definition, since the dependent variable is in levels and not differences, these results are not informative about vulnerability to food price shocks. The results are of interest for two reasons. First, estimating consumption levels regressions constitutes a useful 'quality control' on the consumption data. For example, were we to find no positive association between education and consumption, one might be concerned that our consumption data are not very accurate. Moreover, we consider results with and without the new households included, so as to check if the panel households have systematically different consumption 
levels compared to a random sample drawn from the 2008 population. Second, documenting the correlates of consumption is of interest in and of itself. The analysis sheds some light on, for example, the differences in consumption across households of differing size, a question that has interested economists for a long time (see e.g. Deaton and Paxson, 1998) and the correlation between consumption and education. In all regressions reported below, standard errors are robust to heteroskedasticity.

The results, shown in Table 4, can be summarized as follows: consumption is somewhat lower in households in which the head is female; there is no evidence that consumption varies with the age of the household head; consumption falls with household size, an effect that is particularly strong if there is a large number of casual workers in the household; consumption rises with education and household assets; consumption is lower amongst households in which the head is a casual worker than in households in which the head has a different occupation (including being out of the labor force, which is the reference category in these regressions); and there are no systematic differences across locations, conditional on other explanatory factors. The signs of these partial correlations appear reasonable. Furthermore, the explanatory variables explain around 50 percent of the variation in consumption, which is a fairly good fit. We conclude that the consumption data appear to be of sufficiently high quality for it to be possible to learn about vulnerability from consumption growth regressions. Finally, we observe that the coefficient on the dummy variable for new households is small and completely insignificant, suggesting that there are no systematic differences in consumption across new households and panel households. ${ }^{13}$

(Table 4 here)

(b) Changes in food consumption 
We now analyze how consumption growth rates differ across households depending on observable characteristics. We begin by modeling food consumption growth rates during 2004-2008 as a function of household characteristics. A similar before-after approach has been used by Glewwe and Hall (1998). Results are shown in Table 5, column 1. We find evidence that consumption growth over this period varies with changes in household composition and household size. All coefficients on the change in the number of household members in various occupations are negative, indicating a negative effect of household size on consumption. This effect is strong and statistically significant for casual workers, individuals who are unemployed or out of the labor force, and children. We find a positive and highly significant effect of a change in household assets on consumption growth, but no evidence of systematic growth differences depending on initial assets. The coefficients on primary, secondary and tertiary education are negative, suggesting, somewhat surprisingly, that households headed by individuals with some education have experienced lower consumption growth rates than households in which the head has no education. Consumption growth varies across occupations of the household heads. In all the regressions shown in this section, the reference category (omitted dummy) consists of household heads out of the labor force. Casual workers stand out as being the job category for which consumption developed least favorably during 2004-2008, recording an average growth rate of consumption about 41 percent lower than the reference category. Further analysis into the characteristics of household heads that are out of the labor force suggests that this group has alternative sources of income. For example, remittances from abroad were recorded for 17 percent of the households headed by an individual out of the labor force but only for 10 percent of the households headed by an individual in the labor force. Moreover, there are on average 0.44 more working members in households headed by individuals outside the labor force than in households headed by labor force participants (we can reject the null hypothesis that these two 
sub-samples of households have the same average number of working household members at the 1 percent level).

(Table 5 here)

As discussed in Section 4 we cannot infer from these results how the effect of the food price shock varies with households characteristics, since we do not know how consumption would have developed in the absence of the shock (the counterfactual). The macro nature of the shock implies it is not possible to find a counterfactual in the cross-section, which is why we exploit the panel dimension in the data. The period 2000-2004 was characterized by low average inflation, presenting us with a potentially useful comparison period. We show results for the 2000-2004 period in Table 5, column 2. We are primarily interested in how these results differ from those for 2004-2008. To assess whether these differences are significantly different across the two periods, we pool the data, interact a dummy variable for the shock period with all explanatory variables, and regress the change in log consumption on all explanatory variables and the interaction terms (see eq. [4] above for the exact specification). The estimated coefficients on the interaction terms, and the associated standard errors (which are robust to heteroskedasticity and serial correlation) are shown in Table 5, column 3. Note that, by construction, these coefficients are equal to the difference in the coefficients between 2004-08 and 2000-04. We find that the coefficient on log household assets is higher in the shock period than in the baseline period, and that the difference is significant at the 5 percent level. In the baseline period, the coefficient on assets is negative and significant, possibly reflecting a convergence process by which households that have low assets initially tend to record higher subsequent growth rates. In contrast, in the shock period, the asset coefficient is close to zero. The results for the baseline period thus suggest that the 'normal' relationship 
between initial assets and subsequent growth is negative. Taking this to be the counterfactual relationship, we hence obtain evidence that households with little assets were particularly adversely affected by the food price shock. Households with high initial levels of assets were better able to sustain food consumption during the shock period.

We also find that some of the coefficients on the occupation dummies are significantly different across the two periods, suggesting that labor market status matters for the effect of the food price shock. Recall that the omitted occupation dummy is 'out of the labour force'. Hence, in the baseline period, participating in the labor market tends to lead to higher rates of consumption growth than if you are out of the labor force. In the shock period, however, this pattern is reversed. To the extent that the baseline period is a valid counterfactual, this is interpretable as saying that the food price shock had adverse effects on those in the labour market. The results in column 3 suggest public sector employees (including civil servants) and casual workers were the types of occupations most adversely affected by the food price shock. Different mechanisms clearly operate here. The salaries of civil servants and public sector employees would not have been adjusted instantaneously in response to the food price shock, hence this group of individuals would have seen their real earnings fall as a result of the high inflation. Casual workers, on the other hand, tend to have very uncertain and volatile earnings. The large growth shortfall recorded by this group thus suggests that high income variability in itself is associated with limited ability to smooth consumption, perhaps because of limited access to basic financial services such as overdrafts or savings accounts.

Some of the effects that were found to be statistically significant in the before-after analysis (column (1)) are not significant in the analysis based on the dynamic comparison. There is no evidence that the impact of the food price shock depends on household demographics. The 
coefficients on the age of the household head are not significantly different across the two periods. This is also true for education, which, provided the baseline period is a valid counterfactual, can be interpreted as saying that education has not provided effective insurance against the food price shock. The coefficient on female household head is negative and significant at the 5 percent level. Finally, it should be noted that there are relatively few household heads in our sample that are casual workers (5 percent of the individuals in the 2008 sample; see Table 3). Thus it is possible a small number of outliers drive the results. To investigate this, we exclude from the sub-sample of casual household heads the observations with the highest and lowest consumption growth rates, and re-estimate the regression. We obtain a difference-in-difference point estimate on casual worker equal to -0.73 and a standard error equal to 0.36 . Thus, the main results appear quite robust.

As discussed in Section 5, we have data on the perceived impact of the food price shock on food consumption: very negatively, negatively or not at all. Assigning higher values to less negative outcomes we model this variable using ordered probit. Column (1) in Table 6 shows the results. Most of the findings are similar to those obtained from the dynamic comparison contrasting the shock period to the baseline period. The coefficient on log household assets is positive and highly significant, supporting the notion that household with relatively high levels of assets were less affected by the food price shock. Similar to the results for consumption growth we find a negative and significant (at the 10 percent level) effect of being a casual worker, suggesting that volatile incomes accentuate vulnerability. We find some evidence that the effect of the food price shock was perceived as more severe amongst households with many children. We also find that age has a convex effect on the perceived severity of the effects of the food price shock, suggesting that young household heads were less adversely affected than moderately old heads. 
(Table 6 here)

The final model that we consider in this part of the empirical analysis is a probit regression in which the dependent variable is equal to one if the household did not cut back on the quantity of food served despite the food price shock, and zero otherwise. Results are shown in Table 6, column 2. Again, we find strong evidence that household assets mitigate the effect of the food price shock, and that casual employment of the household head is associated with stronger sensitivity of food consumption to higher food prices. Taken together with the previous results, we thus have strong evidence that households with little assets and uncertain labor market outcomes are particularly vulnerable. The coefficients on age and age squared are negative and positive, respectively, suggesting that young households cope better with the food price shock than moderately old ones.

Why might the effect of the food price shock on consumption vary with household assets? As discussed above, the standard explanation advanced in much of the literature on shocks is that assets enable households to self-insure against shocks. However, recall from the survey data reported in Table 2 that very few households in our sample appear to behave in a way consistent with self-insurance and consumption smoothing. Only about 6 percent of the households claim to have responded to the food price shock by tapping into own assets or taking out a loan. This suggests that there is an alternative underlying reason for the relationship between assets and the impact of the shock observed in the data. Table 7 shows how food consumption patterns compare across households with high and low levels of assets (as measured in 2004), with the cut-off point defined as the sample median of the value of assets. It is clear that households with relatively low levels of assets spend a relatively larger 
share of their total food expenditure on items like cereals, pulses, spices, and coffee and tea, and a relatively smaller share on meat, dairy products and oils and fats. The presence of such differences, which are all statistically significant, suggests that utility over food consumption is non-homothetic. The last column of Table 7 shows price changes in specific food items between December 2006 and December 2008. Strikingly, there is a fairly clear pattern that the price increases have been particularly high for those food items more intensively consumed by the less well off. The price level for cereals, for example, increased by 114 percent while that for spices rose by 176 percent. In contrast, for meat, which is more intensively consumed by richer households, the price level increased by only 47 percent. Figure 2 plots the differences across the two sub-samples in food shares against the food price index. There is a clear negative association between these two variables. That is, in 2004, before food prices began to increase rapidly, the poorest households were allocating larger shares of their food expenditure towards food items for which subsequently prices increased atypically fast. This suggests that the effects documented for assets in the econometric analysis are attributable to underlying differences in the combination of food items consumed, depending on economic status.

(Table 7 here)

(Figure 2 here)

(c) Changes in overall consumption

We now consider a broader definition of the outcome variable, modeling overall consumption growth rather than just food consumption growth. Results are shown in Table 8. Focusing on the estimates in column (3), it is clear that the results are quite similar to those for food consumption in Table 5. Arguably, this is not very surprising given that the average food share 
in the data is as high as 0.78 . However, most of the coefficients in the present regression are less significant than those in the food consumption models, possibly because the effects of higher food prices matter more for food consumption than for the consumption of other products. In fact, only household assets and female head of the household have statistically significant difference-in-difference effects on overall consumption.

(Table 8 here)

\section{(d) Observable shocks}

The evidence reported above thus suggests assets and labor market status play important roles for how severely the food price shock affects households. To probe these results further, we now investigate whether the levels and growth rates of consumption vary with related observable shocks that are idiosyncratic to the household. Data on idiosyncratic shocks were collected for the first time in the 2008/09 survey, thus no panel data exist for these variables. Based on the 2008/09 survey data, we construct five idiosyncratic shock variables: death of a family member; illness of a family member; job loss of a family member; asset loss; and other idiosyncratic shocks, and test whether these impact significantly on consumption. The objective is to measure shocks more directly than has been possible in the analysis above. We control for the full set of variables in $\mathbf{X}_{i, t-1}$ as well as changes in household size, number of children and the number of elderly in the household. We exclude variables from the $\Delta \mathbf{X}_{i t}$ vector that refer to changes in labor market status and changes in assets, since we now measure shocks to employment and assets directly.

Results are shown in Table 9. The control variables are all included in these regressions, but we omit the associated results from the table in order to conserve space. Whether we look at 
food consumption or overall consumption, or levels or growth rates, the result is the same: only job loss of a household member has a statistically significant negative effect. Quantitatively the job loss effect is large, reducing food consumption growth by 28 percent and overall consumption growth by 31 percent. These results indicate, not very surprisingly, that urban households in Ethiopia cannot insure themselves fully against a job loss shock, and that when one occurs, the effects are substantial. One way of interpreting the insignificance of the other types of shocks is that these are easier to cope with than losing one's job.

(Table 9 here)

We have also investigated whether a similar effect of a job loss can be found for 2004. While data on idiosyncratic shocks are not available for this period, we used employment data and created a dummy variable equal to one for households whose members had experienced a job loss and zero otherwise. We found the coefficient on this dummy variable to be negative but smaller in absolute size than what is obtained for 2008/09 and not statistically significant (results are available on request). This suggests becoming unemployed is a particularly serious shock if combined with a food price shock. ${ }^{14}$

\section{CONCLUSIONS}

In this study we use panel data on urban Ethiopian households to examine the effects of the dramatic food price shock in 2008. We study how changes in food consumption and overall consumption relate to household-level variables. We also analyze self-reported data on the qualitative effects of the food price shock on food consumption. 
The evidence indicates that households with low levels of assets have been particularly adversely affected by the food price shock. Overall, we assign a more important role to assets than, for example, do Glewwe and Hall (1998) and Lanjouw and Stern (1993) who, in different settings, find returns to endowments more important. We also find that households headed by a casual worker have been vulnerable to the food price shock. From the point of view of the urban poor, these are troubling results. For this socio-economic group, consumption is oriented towards food items for which price increases have been particularly high, and employment is often unstable because individuals have low skills. Hence, the urban poor appear to have been very adversely affected by the food price shocks.

Education appears to play a small role for the ability to cope with higher food prices, hence there is little evidence in our study supporting Shultz's (1975) hypothesis that education reduces vulnerability. Similarly, household demographics appear to play a limited role for the ability of coping with shocks. This suggests labor supply constraints are not binding. For example, even though there are households in the sample with many children or elderly household members, there is only weak evidence that this has hampered the ability of such households to respond to the shock, relative to other households. Given that food consumption is of primary importance, this is perhaps not very surprising. One possible implication, however, is that the ability of adults to care for the young and the elderly has diminished. Consistent with this, we find that the effect of the food price shock is perceived to be more severe if there are many children in the household. Because we observe no relationship between the number of children and food consumption, this suggests there are other effects on the welfare of households with many children that make life more difficult in general. Almost certainly there is a range of presumably adverse welfare effects of food price shocks that our empirical analysis fails to highlight. 
The fact that aggregate (covariate) shocks are inherently not insurable limits the range of policy instruments that can be used to mitigate the effects of food price shocks. Findings like those in this paper can be used as a basis for the targeting of aid in response to such shocks. One option would be to subsidize the type of food consumed intensively by the poor, provided practical problems such as food leakage (Löfgren and El-Said, 2001) can be overcome. A more serious challenge for policy makers is to reduce the vulnerability of households to high food prices ex ante. One implication of our study is that the creation of good, well-paid and secure jobs reduces vulnerability. Recall that, analyzing the effects of idiosyncratic shocks, we found that experiencing a job loss has a large negative effect on consumption growth, suggesting that households are unable to insure themselves against this type of shock. We have also found that being a casual worker makes one vulnerable to food price shocks. Individuals at the fringe of the labor market may thus face large welfare fluctuations if food prices are volatile. This does not imply that such individuals are worse off on average that those out of the labor force. Rather, it implies that informal, uncertain employment does not provide individuals with a basis for accumulation of resources or stable levels of welfare. Seen in this light, from a welfare point of view the stagnation of the formal sector and the rapid expansion of the informal sector in Ethiopia during the last decade may be quite problematic (Bigsten, Gebreeyesus and Söderbom, 2009). Policies contributing to sustained growth and more jobs in the formal sector would have positive welfare effects through less volatile labor outcomes. 
${ }^{1}$ Dessus et al. (2008), Ivanic and Martin, (2008), Wood et al. (2009) study the implications of rising world food prices on poor households in developing countries, especially the urban poor, and they argue that the negative welfare effects have been tremendous. The data used in these studies do not cover the period of the dramatic global food price increase in 2007-2008.

${ }^{2}$ There is evidence that the unprecedented high rate of inflation in Ethiopia in the past few years eroded living standard of the majority of the urban population. Woldemichael (2008) documents that cumulative salary increment in the government sector (which is the major employer of the labour force in urban areas) between July 2001 and 2007 was about 60 percent, while the general and food price inflation rates during the same period were 96 percent 125 percent respectively.

${ }^{3}$ This was a central theme in the World Development Report 2000/01 (World Bank, 2001).

${ }^{4}$ In empirical research, formulations based on the permanent income hypothesis of Friedman (1957) have been common. Friedman originally argued that rational households with access to perfect markets in insurance and credit will maximize the sum of expected lifetime discounted utility, constrained only by the sum of initial assets, and value of their future savings; their "permanent income".

${ }^{5}$ There are other coping mechanisms too. There is some evidence that households in developing countries attempt to share risk, see e.g. Coate and Ravallion, (1993) and Fafchamps and Lund (2003). Reardon et al. (2007) discuss how rural households may choose to engage in non-farm income generating activities to deal with risk and shocks. Porter (2008) reports some evidence that households in rural Ethiopia divert labour towards relatively higher return activities in order to smooth income during shocks.

${ }^{6}$ Vulnerability is defined by the World Bank (2001) as measuring “...the likelihood that a shock will result in a decline in well-being” (p.139). Note that vulnerability is not synonymous with poverty. For an excellent survey of the micro literature on risk, vulnerability and poverty, see Dercon (2006).

${ }^{7}$ There has been a longstanding debate about whether income or consumption expenditure should be used to measure household welfare. In the context of developing countries, using consumption measures appears to be favoured over using income measures, because income is often underreported and in many cases, volatile and difficult to remember. See Deaton (1997), Deaton and Grosh (2000) for further discussion.

${ }^{8}$ As noted by Glewwe and Hall (1998), household fixed effects in the consumption equation may be caused by heterogeneity across households in the rate of time preference or risk aversion, for example. 
${ }^{9}$ The waves for 2000 and 2004 cover approximately 1,500 households in Addis Ababa, Awassa, Bahir Dar, Dessie, Dire Dawa, Jimma and Mekelle. Still earlier waves of data deriving from the EUSS exist for 1994, 1995 and 1997. See Bigsten and Shimeles (2008) for details on these data. Lack of funding prevented us from covering Bahir Dar, Dire Dawa and Jimma in the 2008/09 survey.

${ }^{10}$ The average share of energy expenditures in total household expenditures is about 6 percent in our sample. Hence, while energy prices have risen rapidly over the sample period, energy expenditures have remained relatively low. Moreover, the data shown in column 2 in Table 1 indicate that few households refer to energy price inflation as big problem. We therefore assume the energy price inflation is a less significant shock for households in urban Ethiopia than the food price inflation.

${ }^{11}$ This figure differs from that reported in Table 2, since new households are excluded here.

12 This household asset variable includes assets such as TV, refrigerator, motor vehicles etc. To express these values in constant 2008 prices, one needs to multiply the prices in constant 1994 prices by 3.16 (authors’ calculations based on the EUSS data; see note 9).

${ }^{13}$ We have also done a pooling test, by interacting the dummy for new households and the explanatory variables and adding these to the baseline specification. The coefficients on the interaction terms are insignificantly different from zero at the 5 percent level of significance, indicating no systematic difference between new households and panel households.

${ }^{14}$ We thank a referee for encouraging us to pursue this. 


\section{REFERENCES}

Ahmed, S. (2008). Global Food Price Inflation: Implications for South Asia, Policy Reactions and Future Challenges. Policy Research Working Paper No. 4796. Washington, DC: The World Bank.

Behrman, J.R., Foster, A.D., \& M. Roswenzweig (1997). Dynamic Savings Decisions in Agricultural Environments With Incomplete Markets. Journal of Economic and Business Statistics, 15(2), 282-92.

Bigsten, A., \& Shimeles, A. (2008). Poverty transition and persistence in Ethiopia. World Development, 36(9), 1559-1584.

Bigsten, A. Gebreeyesus, M., \& Söderbom, M. (2009). Gradual Trade Liberalization and Firm Performance in Ethiopia. CSAE working paper WPS/2009-21. Oxford: Centre for the Study of African Economies, Department of Economics, University of Oxford.

Central Statistics Agency (2008). Country and Regional Level Consumer Price Indices, September 2008. The Federal Democratic Republic of Ethiopia.

Central Statistics Agency (2009). Country and Regional Level Consumer Price Indices, August 2009. The Federal Democratic Republic of Ethiopia.

Central Intelligence Agency (2009). The World Factbook. July, 2009. https://www.cia.gov/library/publications/the-world-factbook/geos/et.html

Coate, S, \& Ravallion, M. (1993). Reciprocity without commitment: Characterization and performance for informal insurance arrangements. Journal of Development Economics 40(1) $1-24$.

Deaton, A (1997). The Analysis of Household Surveys: A Microeconomic Approach to Development Policy. Baltimore: Johns Hopkins University Press. 
Deaton, A. (2002). Guidelines for constructing consumption aggregates for welfare analysis. Living standards measurement study working paper no. 135, World Bank, Washington D.C.

Deaton, A., \& Grosh, M. (2000). Consumption. In: Grosh, M. \& Glewee, P. (Eds): Designing household survey questionnaires for developing countries: lessons from 15 years of the living standards measurement study. Oxford: Oxford University Press.

Deaton, A., \& Paxson, C. (1998). Economies of scale, household size, and the demand for food. Journal of Political Economy 106(5), 897-930.

Dercon, S. (2004). Growth and shocks: evidence from rural Ethiopia. Journal of Development Economics 74(2) 309-329.

Dercon, S. (2006). Vulnerability: a micro perspective. QEH Working Paper No. 149. Oxford: Department of Economics. Oxford University.

Dercon, S., \& Krishnan, P. (1998). Changes in Poverty in Rural Ethiopia 1989-1995: Measurement, Robustness Tests and Decomposition. Working Paper, No. WPS 98/7, center for the study of African economies, University of Oxford,

Dessus, S., Herrera, S., \& de Hoyos, R. (2008). The Impact of Food Inflation in Urban Poverty and Its Monetary Cost. Policy Research Working Paper 4666. Washington, DC: World Bank.

EDRI (2007). Determinants of Inflation in Ethiopia, EDRI. The Federal Democratic Republic of Ethiopia.

Fafchamps, M. (2003). Rural Poverty, Risk and Development. Cheltenham UK: Edward Elgar. Fafchamps, M., \& Lund, S.S. (2003). Risk sharing and quasi-credit. Journal of International Trade and Economic Development, 71(2), 261. 
FAO (2008a). Integrating the Crop and Food Supply and the Emergency Food Security Assessments. FAO/WFP Crop and Food Security Assessment Mission to Ethiopia, http://www.fao.org/decrep/010/ah883e/ah883e00.htm

FAO (2008b). OECD-FAO Agricultural Outlook 2008-2017.

Friedman, M. (1957). A theory of the consumption function. Princeton: Princeton University Press for National Bureau of Economic Research.

Gillbert L. C. (2009). How to understand high food prices. Paper presented on the 2009 ICABR conference, Ravello, Italy, 17-19 June 2009.

Glewwe, P., \& Hall, G. (1998). Are some groups more vulnerable to macroeconomic shocks than others? Hypothesis tests based on panel data from Peru. Journal of Development Economics 56, 181-206.

IMF (2008). Federal Democratic Republic of Ethiopia: 2008 Article IV Consultation Staff Report. IMF Country Report 08/264. Washington DC: International Monetary Fund. Ivanic, M. \& Martin, W. (2008). Implications of Higher Global Food Prices for Poverty in Low-Income Countries. Policy Research Working Paper WPS4594. Washington DC: The World Bank.

Lanjouw, P. \& Stern, N. (1993). Agricultural Change and Inequality in Palanpur 1957-84. In K. Hoff, A. Braverman and J. Stiglitz (eds), The Economics of Rural Organization. Oxford: Oxford University Press.

Lim, Y., \& Townsend, R.M. (1998). General Equilibrium Models of Financial Systems: Theory and Measurement in Village Economies. Review of Economic Dynamics 69(1), 209-244.

Loening, L.J., Durevall, D., \& Birru, Y.A. (2009). Inflation Dynamics and Food Prices in an Agricultural Economy: The Case of Ethiopia. Working Paper 347. Gothenburg: University of Gothenburg. 
Löfgren H., \& El-Said, M. (2001). Food subsidies in Egypt: reform options, distribution and welfare. Food Policy 26: 65-83.

Paxson, C. (1992). Using Weather Variability to Estimate the Response of Savings to Transitory Income in Thailand. American Economic Review 82: 15-33.

Porter, C. (2008). Examining the impact of idiosyncratic and covariate shocks on Ethiopian households’ consumption and income sources. Mimeo. Oxford: Department of Economics. Oxford University.

Ravallion, M. (1998). Poverty lines in theory and practice. LSMS working paper No. 133.

Ravallion, M, \& Lokshin, M. (2001). Identifying welfare effects from subjective questions. Economica, 68: 335-357.

Reardon, T., Nerdegue, C., Barett, B., \& Stamoulis, K. (2007). Household Income Diversification into rural nonfarm activities. In (eds.) Haggblade, S., Hazell, P., Reardon, T., Transforming the Rural nonfarm Economy: opportunities and threats in the developing world (pp. 115-141). Baltimore: John Hopkins Press.

Rosenzweig, M. R.., \& Wolpin, K.I (1993). Credit market constrains, consumption smoothing, and the accumulation of durable production. Journal of Politial Economomy 101(2) 223.

Schultz, T.W. (1975). Human Capital and Disequilibrium. Journal of Economic Literature 13, 827-846.

Skoufias, E., \& Quisumbing, A.R (2005). Consumption insurance and vulnerability to poverty: A synthesis of the Evidence from Bangladesh, Ethiopia, Mali, Mexico and Russia. European Journal of Development Research 17(1) 24-58.

Tadesse, M. 1996. Food consumption and poverty in urban Ethiopia: A preliminary assessment. In: Proceedings of the Fifth Annual Conference on the Ethiopian Economy, ed. Kebede, B., and M. Tadesse. Addis Ababa, Ethiopia.

Townsend, R.M. (1994). Risk and insurance in village India. Econometrica 62(3) 539-591. 
Udry, Christopher (1995). Risk and Saving in Northern Nigeria. American Economic Review 85: 1287-1300.

Wood, B., Nelson, C., \& Nogueira, L. (2009). Food price crisis: Welfare impact on Mexican households. Mimeo. University of Illinois at Urbana-Champaign.

Woldemichael, A. (2008). Food Price Inflation and the Urban Poor in Ethiopia. Paper presented at the $6^{\text {th }}$ International Conference on the Ethiopian Economy, Addis Ababa, July 3-5, 2008.

World Bank (2001). World Development Report 2000/01. Attacking Poverty. New York: Oxford University Press.

World Bank (2007). Ethiopia: Explaining Food Price Inflation Policy Note. Washington DC. Processed. 
Table 1. Incidence of shocks, 2004-2008

\begin{tabular}{lcc}
\hline & $\begin{array}{c}\text { Household experienced } \\
\text { this type of shock }\end{array}$ & $\begin{array}{c}\text { This was the most } \\
\text { influential shock }\end{array}$ \\
\cline { 2 - 3 } Increase in food price & 0.94 & 0.87 \\
Increase in energy price & 0.74 & 0.01 \\
Death of husband & 0.05 & 0.02 \\
Death of wife & 0.02 & 0.004 \\
Death of another member & 0.09 & 0.02 \\
Serious illness of husband & 0.04 & 0.01 \\
Serious illness of wife & 0.06 & 0.01 \\
Serious illness of another member & 0.04 & 0.01 \\
Divorce/separation/abandonment & 0.01 & 0.004 \\
Loss of job of a household member & 0.04 & 0.01 \\
Imprisonment for political reason & 0.004 & 0.003 \\
Destruction or theft of assets & 0.04 & 0.01 \\
Other shock & 0.03 & 0.01 \\
No shock & 0.04 & \\
Observations & & 684 \\
\hline
\end{tabular}

Note: The numbers in the first column do not add up to 1.0 since households could indicate more than one shock. Household indicating there was no shock during the period are excluded from the calculations in the second column. 
Table 2. Coping mechanisms to deal with food price inflation

\begin{tabular}{lc}
\hline & Sample proportion \\
\cline { 2 - 2 } Cut back quantities served per meal & 0.36 \\
Received assistance from relatives and friends & 0.20 \\
Shifted resources from other consumption items & 0.16 \\
Engaged in extra income generating activities & 0.09 \\
Reduced quality and quantity of food purchased & 0.06 \\
Used own saving & 0.04 \\
Received assistance from others & 0.01 \\
Borrowed money against household possessions & 0.02 \\
Received assistance from NGOs & 0.01 \\
Sold household possessions & 0.003 \\
Other & 0.01 \\
Did nothing & 0.04 \\
Observations & \\
\hline
\end{tabular}


Table 3. Summary statistics

\section{Consumption}

Log consumption per adult equivalent

Log food consumption per adult equivalent

Share of food in total expenditure

Food consumption very negatively affected

(1) Year 2008

(2) Year 2004

(3) Year 2000

Food consumption negatively affected

Mean Std Dev Mean Std Dev Mean Std Dev

Consumed less food because of food price shock

$\begin{array}{llllll}4.69 & 0.62 & 4.75 & 0.70 & 4.67 & 0.81 \\ 4.44 & 0.63 & 4.40 & 0.72 & 4.31 & 0.81 \\ 0.78 & 0.08 & 0.72 & 0.11 & 0.71 & 0.14 \\ 0.60 & & & & & \\ 0.29 & & & & & \\ 0.32 & & & & & \end{array}$

\section{Household assets}

Owns a house

0.48

log household assets

7.29

1.43

0.47

0.45

Head of the household

Female

0.50

54.9

Age

0.39

0.39

0.11

0.11

0.43

0.23

0.17

0.12

0.05

1.43

7.43

1.54

6.86

1.85

Primary schooling completed

13.8

0.48

0.43

Secondary schooling completed

51.3

13.5

50.8

Out of the labor force

0.37

0.54

0.40

0.20

0.15

0.19

0.07

0.08

0.41

0.24

Public sector employee

0.25

0.19

Private sector employee

0.18

0.10

Casual worker

0.08

0.06

Household size \& occupation of household members

Household size

5.39

2.58

5.69

2.46

6.06

2.50

Number of self-employed

0.23

0.48

0.19

0.47

0.23

0.69

Number of public sector employees

$0.28 \quad 0.58$

0.31

0.61

$0.11 \quad 0.34$

Number of private sector employees

2.03

1.99

2.13

1.63

2.33

1.76

Number of casual workers

0.59

0.36

0.70

$0.27 \quad 0.60$

Number of unemployed or out of the labor force

0.19

0.54

0.15

0.48

0.17

0.54

Number of children

$1.03 \quad 1.08$

1.53

1.36

1.90

1.59

Number of elderly

0.05

0.23

0.03

0.18

0.06

0.30

Addis Ababa

0.61

0.61

0.71

0.13

0.13

0.09

Dessie

0.13

0.13

0.09

Mekelle

0.13

0.13

0.10

Observations 557 557 427

Note: Standard deviations omitted for dummy variables. 
Table 4: Covariates of Consumption 2008

\section{Household assets}

Owns a house

Log of household assets

\section{Head of the household}

Female

Age

Age squared / 100

Primary schooling completed

Secondary schooling completed

Tertiary schooling completed

Self employed

Public sector employee

Private sector employee

Casual worker

\section{Household members}

Number of self-employed

Number of public sector employees

Number of private sector employees

Number of casual workers

Number of unemployed or out of the labor force

Number of children

Number of elderly

\section{Location and sampling status}

Addis Ababa

Awassa

Dessie

New household

\begin{tabular}{|c|c|c|c|c|c|c|c|}
\hline \multicolumn{2}{|c|}{ (1) Food consumption } & \multicolumn{2}{|c|}{ (2) Food consumption } & \multicolumn{2}{|c|}{ (3) Overall consumption } & \multicolumn{2}{|c|}{ (4) Overall consumption } \\
\hline Coefficient & Std error & Coefficient & Std error & Coefficient & Std error & Coefficient & Std error \\
\hline 0.059 & 0.044 & 0.060 & 0.040 & $0.072^{*}$ & 0.042 & $0.077 * *$ & 0.037 \\
\hline $0.190 * * *$ & 0.018 & $0.204 * * *$ & 0.018 & $0.207 * * *$ & 0.018 & $0.216^{* * *}$ & 0.017 \\
\hline$-0.125^{* *}$ & 0.053 & $-0.148 * * *$ & 0.047 & $-0.107 * *$ & 0.048 & $-0.131 * * *$ & 0.043 \\
\hline-0.008 & 0.013 & -0.016 & 0.010 & -0.011 & 0.011 & $-0.016 *$ & 0.009 \\
\hline 0.008 & 0.012 & 0.014 & 0.009 & 0.010 & 0.010 & $0.015^{*}$ & 0.008 \\
\hline-0.004 & 0.051 & -0.025 & 0.046 & 0.001 & 0.048 & -0.015 & 0.043 \\
\hline 0.119 & 0.077 & 0.075 & 0.070 & 0.112 & 0.069 & 0.075 & 0.063 \\
\hline $0.308 * * *$ & 0.083 & $0.252 * * *$ & 0.077 & $0.315^{* * *}$ & 0.078 & $0.254 * * *$ & 0.072 \\
\hline $0.118^{* *}$ & 0.058 & 0.061 & 0.053 & $0.109 *$ & 0.054 & 0.067 & 0.049 \\
\hline-0.030 & 0.068 & -0.036 & 0.062 & -0.032 & 0.064 & -0.033 & 0.058 \\
\hline 0.003 & 0.077 & 0.002 & 0.070 & -0.004 & 0.071 & -0.005 & 0.064 \\
\hline-0.132 & 0.109 & $-0.209 * *$ & 0.093 & -0.166 & 0.105 & $-0.229 * * *$ & 0.088 \\
\hline$-0.074^{*}$ & 0.038 & $-0.060 *$ & 0.034 & $-0.092 * *$ & 0.036 & $-0.076^{* *}$ & 0.031 \\
\hline-0.009 & 0.032 & -0.010 & 0.028 & -0.017 & 0.031 & -0.019 & 0.027 \\
\hline$-0.085 * * *$ & 0.022 & $-0.078 * * *$ & 0.019 & $-0.090 * * *$ & 0.021 & $-0.083 * * *$ & 0.017 \\
\hline$-0.232 * * *$ & 0.037 & $-0.214 * * *$ & 0.034 & $-0.228 * * *$ & 0.034 & $-0.218 * * *$ & 0.032 \\
\hline$-0.114 * * *$ & 0.016 & $-0.105^{* * *}$ & 0.014 & $-0.117 * * *$ & 0.014 & $-0.110 * * *$ & 0.012 \\
\hline$-0.147 * * *$ & 0.018 & $-0.128 * * *$ & 0.016 & $-0.165 * * *$ & 0.018 & $-0.145^{* * *}$ & 0.016 \\
\hline-0.046 & 0.072 & -0.031 & 0.063 & -0.082 & 0.074 & -0.058 & 0.061 \\
\hline-0.099 & 0.064 & $-0.118 *$ & 0.059 & -0.034 & 0.060 & -0.046 & 0.054 \\
\hline-0.067 & 0.075 & -0.087 & 0.065 & -0.024 & 0.070 & -0.029 & 0.060 \\
\hline \multirow[t]{2}{*}{-0.093} & 0.078 & -0.110 & 0.072 & -0.064 & 0.071 & -0.067 & 0.066 \\
\hline & & -0.021 & 0.049 & & & 0.001 & 0.044 \\
\hline 557 & & 685 & & 557 & & 685 & \\
\hline 0.46 & & 0.46 & & 0.52 & & 0.52 & \\
\hline
\end{tabular}

Observations

0.46

0.46

0.52

0.52

Note: All models are estimated using OLS with the dependent variable expressed in logarithmic form. Standard errors are robust to heteroskedasticity.. Significance at the 1 percent, 5 percent, 10 percent level is indicated by ***,**, *, respectively. An intercept is included in all model specifications. 


\section{A. VARIABLES IN LEVELS}

\section{Household assets}

Owns a house

Log of household assets

Head of the household

Female

Age

Age squared / 100

Primary schooling completed

Secondary schooling completed

Tertiary schooling completed

Self employed

Public sector employee

Private sector employee

Casual worker

\section{Household members}

Number of self-employed

Number of public sector employees

Number of private sector employees

Number of casual workers

Number of unemployed or out of the labor force

Number of children

Number of elderly

\section{Location and time}

Addis Ababa

Awassa

Dessie

2004-08 Period

\section{B. VARIABLES IN FIRST DIFFERENCES}

\section{Household assets}

$\Delta$ Owns a house

$\Delta$ Log of household assets

\section{Head of the household}

$\Delta$ Self employed

$\Delta$ Public sector employee

$\Delta$ Private sector employee

$\Delta$ Casual worker

\section{Household members}

$\Delta$ Number of self-employed

$\Delta$ Number of public sector employees

$\Delta$ Number of private sector employees

$\Delta$ Number of casual workers

$\Delta$ Number of unemployed or out of the labor force

$\Delta$ Number of children

$\Delta$ Number of elderly

\section{(1) Consumption} growth 2004-08

Coef

\section{(2) Consumption} growth 2000-04

(3) Difference in Difference
Coef

Std err

$\begin{array}{cccccc}-0.086 & 0.075 & 0.033 & 0.084 & -0.120 & 0.133 \\ 0.037 & 0.031 & -0.080^{* *} & 0.033 & 0.117^{* *} & 0.052 \\ & & & & & \\ -0.110 & 0.078 & 0.173^{* *} & 0.087 & -0.283^{* *} & 0.131 \\ -0.023 & 0.015 & 0.008 & 0.021 & -0.031 & 0.027 \\ 0.020 & 0.014 & -0.003 & 0.020 & 0.023 & 0.025 \\ -0.145^{*} & 0.077 & -0.035 & 0.106 & -0.110 & 0.133 \\ -0.204^{*} & 0.120 & -0.018 & 0.113 & -0.186 & 0.185 \\ -0.259^{*} & 0.139 & 0.001 & 0.159 & -0.261 & 0.229 \\ 0.004 & 0.102 & 0.162 & 0.128 & -0.157 & 0.185 \\ -0.091 & 0.114 & 0.356^{* *} & 0.138 & -0.447 * * & 0.201 \\ 0.044 & 0.151 & 0.151 & 0.192 & -0.107 & 0.267 \\ -0.524^{* *} & 0.221 & 0.219 & 0.266 & -0.744 * * & 0.378 \\ & & & & & \\ -0.046 & 0.088 & 0.028 & 0.083 & -0.074 & 0.145 \\ 0.048 & 0.061 & 0.077 & 0.114 & -0.028 & 0.140 \\ 0.061 & 0.053 & -0.026 & 0.076 & 0.087 & 0.103 \\ 0.027 & 0.072 & -0.069 & 0.096 & 0.096 & 0.122 \\ -0.002 & 0.023 & 0.013 & 0.029 & -0.015 & 0.042 \\ 0.000 & 0.030 & 0.007 & 0.037 & -0.007 & 0.057 \\ 0.016 & 0.148 & 0.063 & 0.205 & -0.047 & 0.272 \\ & & & & & \\ -0.095 & 0.107 & 0.246 * & 0.135 & -0.342^{*} & 0.206 \\ -0.050 & 0.118 & 0.215 & 0.159 & -0.265 & 0.229 \\ 0.040 & 0.121 & 0.119 & 0.177 & -0.079 & 0.251 \\ & & & & 0.807 & 0.779\end{array}$

$\begin{array}{lllrrr}0.018 & 0.107 & 0.037 & 0.155 & -0.019 & 0.177 \\ 0.115^{* * *} & 0.031 & 0.042 & 0.034 & 0.073 & 0.047 \\ & & & & & \\ 0.075 & 0.096 & 0.081 & 0.112 & -0.005 & 0.150 \\ 0.172 & 0.109 & 0.118 & 0.114 & 0.054 & 0.150 \\ 0.189^{*} & 0.111 & 0.123 & 0.165 & 0.066 & 0.195 \\ -0.053 & 0.176 & 0.220 & 0.252 & -0.274 & 0.302 \\ & & & & & \\ -0.018 & 0.064 & -0.052 & 0.089 & 0.034 & 0.110 \\ -0.021 & 0.051 & -0.084 & 0.063 & 0.062 & 0.080 \\ -0.059 & 0.036 & -0.030 & 0.052 & -0.029 & 0.065 \\ -0.109^{*} & 0.063 & -0.078 & 0.078 & -0.030 & 0.098 \\ -0.103^{* * *} & 0.021 & -0.102^{* * *} & 0.028 & -0.001 & 0.034 \\ -0.104^{* * *} & 0.035 & -0.145 * * * & 0.039 & 0.041 & 0.054 \\ -0.105 & 0.164 & -0.046 & 0.198 & -0.059 & 0.243\end{array}$

R-squared

0.16

0.20

557

427

984

Note: Standard errors in (1) and (2) are robust to heteroskedasticity. Standard errors in (3) are robust to heteroskedasticity and autocorrelation. Significance at the 1 percent, 5 percent, 10 percent level is indicated by ***, **, *, respectively. An intercept is included in all model specifications. Column (3) shows the estimated coefficients on interaction terms between a dummy for the period 2004/08 and all explanatory variables, in a regression pooling the data underlying (1) and (2). 


\begin{tabular}{|c|c|c|c|c|}
\hline & \multicolumn{2}{|c|}{$\begin{array}{l}\text { (1) Perceived effect (ordered } \\
\text { probit) }\end{array}$} & \multicolumn{2}{|c|}{$\begin{array}{l}\text { (1) Did not cut back on quantity } \\
\text { of food consumed (probit) }\end{array}$} \\
\hline & Coefficient & Standard error & Coefficient & Standard error \\
\hline \multicolumn{5}{|l|}{ A. VARIABLES IN LEVELS } \\
\hline \multicolumn{5}{|l|}{ Household assets } \\
\hline Owns a house & 0.059 & 0.128 & 0.204 & 0.147 \\
\hline Log of household assets & $0.407 * * *$ & 0.059 & $0.266 * * *$ & 0.065 \\
\hline \multicolumn{5}{|l|}{ Head of the household } \\
\hline Female & 0.052 & 0.147 & -0.198 & 0.149 \\
\hline Age & $-0.068 * * *$ & 0.025 & $-0.069 * *$ & 0.032 \\
\hline Age squared / 100 & $0.067 * *$ & 0.026 & $0.064 * *$ & 0.030 \\
\hline Primary schooling completed & -0.027 & 0.159 & 0.158 & 0.151 \\
\hline Secondary schooling completed & -0.084 & 0.218 & 0.001 & 0.235 \\
\hline Tertiary schooling completed & 0.303 & 0.277 & 0.225 & 0.321 \\
\hline Self employed & 0.263 & 0.194 & -0.121 & 0.202 \\
\hline Public sector employee & -0.009 & 0.224 & -0.053 & 0.233 \\
\hline Private sector employee & 0.033 & 0.247 & -0.192 & 0.285 \\
\hline Casual worker & $-0.826 *$ & 0.484 & $-1.034^{* *}$ & 0.424 \\
\hline \multicolumn{5}{|l|}{ Household members } \\
\hline Number of self-employed & -0.017 & 0.139 & 0.234 & 0.172 \\
\hline Number of public sector employees & 0.006 & 0.118 & -0.065 & 0.132 \\
\hline Number of private sector employees & 0.039 & 0.093 & 0.115 & 0.098 \\
\hline Number of casual workers & 0.019 & 0.146 & 0.025 & 0.153 \\
\hline Number of unemployed or out of the labor force & -0.007 & 0.040 & -0.065 & 0.046 \\
\hline Number of children & $-0.118 * *$ & 0.061 & -0.027 & 0.063 \\
\hline Number of elderly & 0.336 & 0.277 & -0.016 & 0.379 \\
\hline \multicolumn{5}{|l|}{ Location and time } \\
\hline Addis Ababa & $1.277 * * *$ & 0.256 & $-0.787 * * *$ & 0.209 \\
\hline Awassa & $2.405 * * *$ & 0.306 & $-0.439 *$ & 0.253 \\
\hline Dessie & $0.843 * * *$ & 0.290 & 0.010 & 0.258 \\
\hline \multicolumn{5}{|l|}{ B. VARIABLES IN FIRST DIFFERENCES } \\
\hline \multicolumn{5}{|l|}{ Household assets } \\
\hline$\Delta$ Owns a house & 0.312 & 0.209 & -0.001 & 0.217 \\
\hline$\Delta$ Log of household assets & $0.326 * *$ & 0.059 & $0.359 * * *$ & 0.067 \\
\hline \multicolumn{5}{|l|}{ Head of the household } \\
\hline$\Delta$ Self employed & 0.223 & 0.168 & 0.057 & 0.175 \\
\hline$\Delta$ Public sector employee & 0.171 & 0.224 & 0.233 & 0.233 \\
\hline$\Delta$ Private sector employee & 0.122 & 0.189 & 0.096 & 0.227 \\
\hline$\Delta$ Casual worker & -0.141 & 0.321 & -0.095 & 0.298 \\
\hline \multicolumn{5}{|l|}{ Household members } \\
\hline$\Delta$ Number of self-employed & -0.007 & 0.121 & -0.049 & 0.140 \\
\hline$\Delta$ Number of public sector employees & -0.038 & 0.106 & -0.079 & 0.115 \\
\hline$\Delta$ Number of private sector employees & -0.003 & 0.060 & -0.091 & 0.073 \\
\hline$\Delta$ Number of casual workers & 0.108 & 0.124 & -0.026 & 0.116 \\
\hline$\Delta$ Number of unemployed or out of the labor force & 0.003 & 0.035 & $-0.061 *$ & 0.037 \\
\hline$\Delta$ Number of children & $-0.237 * * *$ & 0.068 & -0.093 & 0.068 \\
\hline$\Delta$ Number of elderly & 0.021 & 0.210 & 0.091 & 0.260 \\
\hline Pseudo R-squared & 0.23 & & 0.16 & \\
\hline Observations & 557 & & 557 & \\
\hline
\end{tabular}

Note: Standard errors in (1) and (2) are robust to heteroskedasticity. Significance at the 1 percent, 5 percent, 10 percent level is indicated by ***, **, *, respectively. An intercept is included in both model specifications. The dependent variable in (1) is coded as follows: 0 - very negatively; 1 - negatively; 2 - not at all. The dependent variable in (2) is a dummy variable equal to 1 if the household did not cut back on the quantity of food consumed despite the food price shock. 


\begin{tabular}{lccccc}
\hline \multicolumn{2}{c}{ Share in total food spending } & & & \\
& $\begin{array}{c}\text { Sub-sample: } \\
\text { Assets high }\end{array}$ & $\begin{array}{c}\text { Sub-sample: } \\
\text { Assets low }\end{array}$ & $\begin{array}{l}\text { Difference in } \\
\text { means }\end{array}$ & $\begin{array}{c}\mathrm{H}_{0} \text { : Common } \\
\text { mean (t-value) }\end{array}$ & $\begin{array}{c}\text { Price Index } \\
\text { December } \\
2008^{(a)}\end{array}$ \\
\cline { 2 - 6 } Cereals & 0.307 & 0.350 & -0.044 & -4.10 & 214.3 \\
Pulses & 0.080 & 0.093 & -0.012 & -2.54 & 162.9 \\
Bread and Other Prepared Food & 0.097 & 0.090 & 0.007 & 0.85 & 225.0 \\
Meat & 0.072 & 0.034 & 0.037 & 6.66 & 146.6 \\
Milk, Cheese and Egg & 0.025 & 0.014 & 0.011 & 4.35 & 150.6 \\
Oils and Fats & 0.110 & 0.091 & 0.019 & 4.23 & 166.2 \\
Vegetables and Fruits & 0.077 & 0.070 & 0.007 & 1.66 & 147.0 \\
Spices & 0.089 & 0.108 & -0.020 & -3.61 & 275.5 \\
Coffee and Tea Leaves & 0.042 & 0.062 & -0.019 & -5.27 & 138.6 \\
Drinks & 0.020 & 0.008 & 0.012 & 5.43 & 174.3 \\
Other Food Items & 0.081 & 0.080 & 0.001 & 0.17 & 158.4 \\
\hline
\end{tabular}

Note: To compute the share spent on various food items in total food spending, we use the entire sample for 2004. We divide the sample into households with high and low levels of assets, using the median of asset values as the cut-off point.

(a) The price indices for the food items are from official data published by the Central Statistics Agency on September 9, 2009 using December 2006 as base year. 


\section{A. VARIABLES IN LEVELS}

\section{Household assets}

Owns a house

Log of household assets

\section{Head of the household}

Female

Age

Age squared / 100

Primary schooling completed

Secondary schooling completed

Tertiary schooling completed

Self employed

Public sector employee

Private sector employee

Casual worker

\section{Household members}

Number of self-employed

Number of public sector employees

Number of private sector employees

Number of casual workers

Number of unemployed or out of the labor force

Number of children

Number of elderly

\section{Location and time}

Addis Ababa

Awassa

Dessie

2004-08 Period

\section{B. VARIABLES IN FIRST DIFFERENCES}

\section{Household assets}

$\Delta$ Owns a house

$\Delta$ Log of household assets

\section{Head of the household}

$\Delta$ Self employed

$\Delta$ Public sector employee

$\Delta$ Private sector employee

$\Delta$ Casual worker

\section{Household members}

$\Delta$ Number of self-employed

$\Delta$ Number of public sector employees

$\Delta$ Number of private sector employees

$\Delta$ Number of casual workers

$\Delta$ Number of unemployed or out of the labor force

$\Delta$ Number of children

$\Delta$ Number of elderly

$\begin{array}{llll}\text { (1) Consumption } & \text { (2) Consumption } & \text { (3) Difference in } \\ \text { growth 2004-08 } & \text { growth 2000-04 } & \text { Difference } \\ \text { Coef } & \text { Std err } & \text { Coef } \quad \text { Std err } & \text { Coef } \quad \text { Std err }\end{array}$

$\begin{array}{llllll}-0.104 & 0.068 & 0.060 & 0.083 & -0.164 & 0.126 \\ 0.037 & 0.028 & -0.065^{* *} & 0.031 & 0.102^{* *} & 0.050 \\ & & & & & \\ -0.069 & 0.069 & 0.159 * * & 0.079 & -0.228^{* *} & 0.117 \\ -0.014 & 0.014 & 0.010 & 0.022 & -0.024 & 0.027 \\ 0.012 & 0.013 & -0.008 & 0.020 & 0.020 & 0.025 \\ -0.145^{* *} & 0.069 & -0.070 & 0.103 & -0.074 & 0.123 \\ -0.169 & 0.107 & -0.022 & 0.113 & -0.147 & 0.174 \\ -0.207 & 0.127 & -0.083 & 0.167 & -0.123 & 0.227 \\ 0.012 & 0.091 & 0.071 & 0.129 & -0.059 & 0.177 \\ -0.065 & 0.102 & 0.204 & 0.135 & -0.268 & 0.188 \\ 0.030 & 0.141 & -0.032 & 0.162 & 0.062 & 0.240 \\ -0.441^{* *} & 0.207 & 0.122 & 0.255 & -0.563 & 0.362\end{array}$

$\begin{array}{rrrrrr}-0.070 & 0.079 & 0.060 & 0.078 & -0.130 & 0.129 \\ 0.033 & 0.055 & 0.030 & 0.104 & 0.003 & 0.127 \\ 0.035 & 0.047 & -0.029 & 0.075 & 0.064 & 0.101 \\ 0.036 & 0.065 & -0.058 & 0.091 & 0.094 & 0.118 \\ 0.000 & 0.021 & 0.003 & 0.028 & -0.002 & 0.040 \\ -0.013 & 0.027 & 0.013 & 0.035 & -0.026 & 0.053 \\ 0.040 & 0.135 & -0.089 & 0.182 & 0.129 & 0.241 \\ & & & & & \\ -0.060 & 0.099 & 0.177 & 0.131 & -0.238 & 0.196 \\ -0.047 & 0.108 & 0.217 & 0.156 & -0.265 & 0.219 \\ 0.095 & 0.108 & 0.173 & 0.173 & -0.078 & 0.238 \\ & & & & 0.396 & 0.780\end{array}$

$\begin{array}{llllrl}-0.019 & 0.101 & 0.147 & 0.151 & -0.166 & 0.173 \\ 0.116^{* * *} & 0.028 & 0.045 & 0.032 & 0.071 & 0.044\end{array}$

$\begin{array}{llllll}0.051 & 0.088 & 0.044 & 0.108 & 0.007 & 0.140\end{array}$

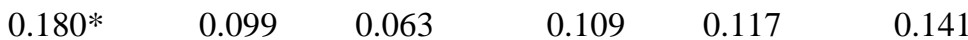

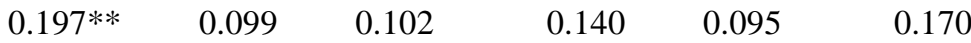

$\begin{array}{llllll}-0.049 & 0.159 & 0.124 & 0.249 & -0.173 & 0.290\end{array}$

$\begin{array}{llllrl}-0.047 & 0.060 & -0.037 & 0.083 & -0.010 & 0.101 \\ -0.026 & 0.045 & -0.064 & 0.067 & 0.038 & 0.078 \\ -0.073 * * & 0.033 & -0.038 & 0.051 & -0.035 & 0.063 \\ -0.089 & 0.060 & -0.081 & 0.067 & -0.008 & 0.088 \\ -0.108 * * * & 0.019 & -0.109 * * * & 0.028 & 0.001 & 0.032 \\ -0.122^{* * *} & 0.031 & -0.151^{* * *} & 0.040 & 0.029 & 0.052 \\ -0.097 & 0.159 & -0.039 & 0.162 & -0.058 & 0.217\end{array}$

R-squared

Observations 557 427 984

Note: Standard errors in (1) and (2) are robust to heteroskedasticity. Standard errors in (3) are robust to heteroskedasticity and autocorrelation. Significance at the 1 percent, 5 percent, 10 percent level is indicated by ***, **, *, respectively. An intercept is included in all model specifications. Column (3) shows the estimated coefficients on interaction terms between a dummy for the period 2004/08 and all explanatory variables, in a regression pooling the data underlying (1) and (2). 
Table 9: The Effects of Idiosyncratic shocks

\begin{tabular}{|c|c|c|c|c|c|c|c|c|}
\hline & \multicolumn{2}{|c|}{ (1) Food consumption } & \multicolumn{2}{|c|}{$\begin{array}{l}\text { (2) Change in food } \\
\text { consumption }\end{array}$} & \multicolumn{2}{|c|}{ (3) Overall consumption } & \multicolumn{2}{|c|}{$\begin{array}{l}\text { (4) Change in overall } \\
\text { consumption }\end{array}$} \\
\hline & Coefficient & Std error & Coefficient & Std error & Coefficient & Std error & Coefficient & Std error \\
\hline Death of family member & -0.135 & 0.083 & 0.080 & 0.093 & -0.111 & 0.078 & 0.085 & 0.085 \\
\hline Illness of family member & -0.027 & 0.069 & 0.030 & 0.114 & 0.006 & 0.062 & 0.029 & 0.104 \\
\hline Job loss of household member & $-0.225^{*}$ & 0.129 & $-0.322 *$ & 0.167 & $-0.252 * *$ & 0.124 & $-0.372 * *$ & 0.166 \\
\hline Asset loss & 0.129 & 0.092 & -0.288 & 0.189 & 0.136 & 0.091 & -0.230 & 0.161 \\
\hline Other idiosyncratic shocks & 0.133 & 0.140 & 0.248 & 0.161 & 0.090 & 0.136 & 0.253 & 0.154 \\
\hline \multicolumn{9}{|l|}{ Control variables } \\
\hline Household assets & Yes & & Yes & & Yes & & Yes & \\
\hline Characteristics of the head & Yes & & Yes & & Yes & & Yes & \\
\hline Household members & Yes & & Yes & & Yes & & Yes & \\
\hline Location & Yes & & Yes & & Yes & & Yes & \\
\hline Change in household size & Yes & & Yes & & Yes & & Yes & \\
\hline $\begin{array}{l}\text { Change in number of children } \\
\text { and elderly }\end{array}$ & Yes & & Yes & & Yes & & Yes & \\
\hline Observations & 557 & & 557 & & 557 & & 557 & \\
\hline R-squared & 0.37 & & 0.13 & & 0.43 & & 0.15 & \\
\hline
\end{tabular}

Note: Standard errors are robust to heteroskedasticity. Significance at the 1 percent, 5 percent, 10 percent level is indicated by ***, **, *, respectively.

An intercept and a set of control variables are included in all model specifications. 


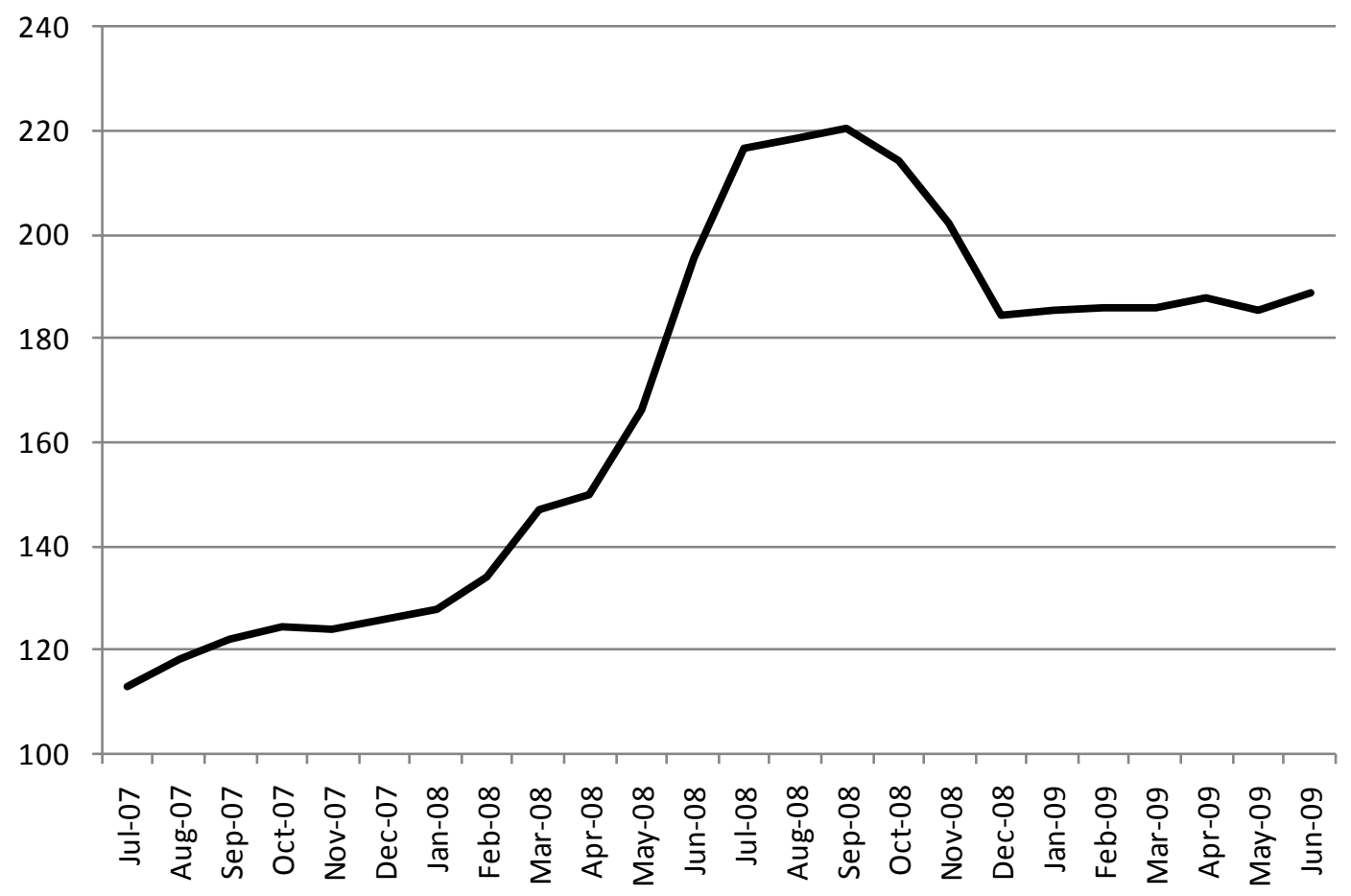

Figure 1: Food Price Index in Ethiopia, July 2007 - June 2009

Note: The graph shows the price index for food for Ethiopia. December $2006=100$. Source: Central Statistics Agency (2008, 2009) 


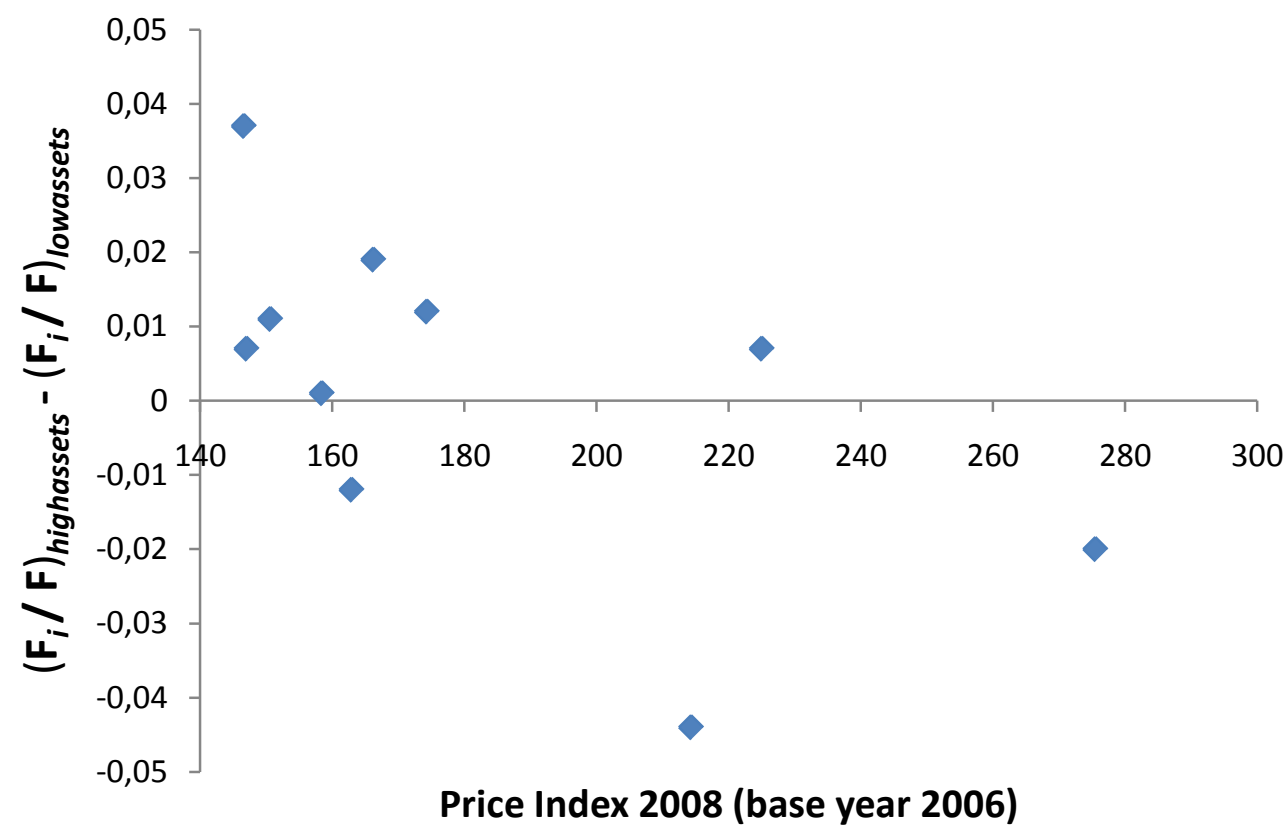

Figure 2: Food consumption patterns by economic status, and food price inflation

Note: The vertical axis measures the difference in average food shares across households with high and low levels of assets, for eleven food items as listed in Table 7. That is, $\left(\mathbf{F}_{\boldsymbol{i}} / \mathbf{F}\right)_{\text {highassets }}-\left(\mathbf{F}_{\boldsymbol{i}} / \mathbf{F}\right)_{\text {lowassets }}$

is defined as the "difference in means" for food item $i$, shown in the fourth column of Table 7 . The horizontal graph measures the price index for these food items over the period December 2006 - December 2008. 


\section{Appendix}

\section{Consumption aggregation and adult equivalences}

We computed aggregate household consumption expenditure by adding up reported household expenditure on food and non-food items. The non-food component of consumption includes expenditures on items such as; clothing, footwear, energy, personal care, utilities, health and education. We excluded expenditure on consumer durables. According to Deaton (2002), from the perspective of welfare analysis, it is the value of services that flows from ownership of these consumer durables that should enter the aggregation of consumption expenditure. This was not possible in our analysis because we didn't have information that is useful to impute depreciation rate of household fixed assets. This is unlikely to distort the values of the aggregated consumption expenditure because the value of expenditure that goes to durables goods in Ethiopia is insignificant (Tadesse, 1996).

Aggregate household consumption expenditure is converted into adult equivalences to adjust for household size and composition using the method proposed by Dercon and Krishnan (1998). Moreover, to allow for temporal and spatial comparisons of consumption among households, we computed real household consumption by deflating nominal consumption using price indices constructed from the survey. We specifically took the poverty line of Addis Ababa (the capital city) as the reference city against which poverty lines in all other cities in all rounds are expressed and computed price indices accordingly. We then use the price deflators to convert nominal consumption expenditures to real. Thus our household consumption variable is adjusted for spatial as well as temporal price differences (see Ravallion, 1998, for a detailed discussion on the use of poverty lines as deflators). 
Table A.1 Selected Macroeconomic Indicators of Ethiopia 2000-2008

\begin{tabular}{|c|c|c|c|c|c|c|c|c|c|c|c|}
\hline Variable & Units & Scale & 2000 & 2001 & 2002 & 2003 & 2004 & 2005 & 2006 & 2007 & 2008 \\
\hline GDP, constant prices & National currency & Billions & 64.40 & 69.36 & 70.22 & 67.76 & 74.40 & 83.80 & 93.47 & 104.20 & 116.30 \\
\hline GDP, constant prices & $\begin{array}{l}\text { Annual percent } \\
\text { change }\end{array}$ & & \multirow{2}{*}{$\begin{array}{r}5.93 \\
64.40\end{array}$} & 7.71 & 1.24 & -3.51 & 9.80 & 12.64 & 11.54 & 11.47 & 11.61 \\
\hline GDP, current prices & National currency & Billions & & 65.69 & 63.46 & 68.90 & 86.66 & 106.47 & 131.67 & 170.92 & 239.13 \\
\hline GDP, current prices & U.S. dollars & Billions & 7.90 & 7.88 & 7.43 & 8.03 & 10.05 & 12.31 & 15.17 & 19.43 & 25.66 \\
\hline GDP, deflator & Index & & 100.00 & 94.70 & 90.38 & 101.69 & 116.48 & 127.05 & 140.87 & 164.04 & 205.62 \\
\hline GDP per capita, constant prices & National currency & Units & \multirow{3}{*}{$\begin{array}{r}1014.14 \\
1014.14 \\
124.40\end{array}$} & $1,060.497$ & $1,044.618$ & 980.51 & $1,047.300$ & $1,147.591$ & $1,245.138$ & $1,350.171$ & $1,468.752$ \\
\hline GDP per capita, current prices & National currency & Units & & $1,004.317$ & 944.10 & 997.05 & $1,219.941$ & $1,458.011$ & $1,753.967$ & $2,214.790$ & $3,020.055$ \\
\hline GDP per capita, current prices & U.S. dollars & Units & & 120.47 & 110.51 & 116.20 & 141.53 & 168.52 & 202.05 & 251.79 & 324.05 \\
\hline GDP based on PPP & $\begin{array}{l}\text { Current international } \\
\text { dollar }\end{array}$ & Billions & 29.59 & 32.63 & 33.61 & 33.12 & 40.76 & 47.24 & 54.39 & 62.26 & 71.00 \\
\hline $\begin{array}{l}\text { GDP based on PPP per capita } \\
\text { GDP }\end{array}$ & $\begin{array}{l}\text { Current international } \\
\text { dollar }\end{array}$ & Units & 465.92 & 498.90 & 500.01 & 479.31 & 573.81 & 646.85 & 724.44 & 806.70 & 896.64 \\
\hline $\begin{array}{l}\text { GDP based on PPP share of } \\
\text { world total }\end{array}$ & Percent & & 0.07 & 0.08 & 0.07 & 0.07 & 0.08 & 0.08 & 0.09 & 0.10 & 0.10 \\
\hline Implied PPP conversion rate & & & 2.18 & 2.01 & 1.89 & 2.08 & 2.13 & 2.25 & 2.42 & 2.75 & 3.37 \\
\hline $\begin{array}{l}\text { Inflation, average consumer } \\
\text { prices }\end{array}$ & Index, $2000=100$ & & 100.00 & 94.79 & 87.94 & 101.18 & 109.90 & 117.42 & 131.81 & 152.69 & 191.34 \\
\hline $\begin{array}{l}\text { Inflation, average consumer } \\
\text { prices }\end{array}$ & $\begin{array}{l}\text { Annual percent } \\
\text { change }\end{array}$ & & 6.16 & -5.21 & -7.22 & 15.06 & 8.62 & 6.84 & 12.26 & 15.84 & 25.32 \\
\hline $\begin{array}{l}\text { Inflation, end of period consumer } \\
\text { prices }\end{array}$ & Index, $2000=100$ & & 100.00 & 88.57 & 87.67 & 108.28 & 110.17 & 124.48 & 138.88 & 159.88 & 248.24 \\
\hline $\begin{array}{l}\text { Inflation, end of period consumer } \\
\text { prices }\end{array}$ & $\begin{array}{l}\text { Annual percent } \\
\text { change }\end{array}$ & & 0.27 & -11.43 & -1.02 & 23.51 & 1.75 & 12.99 & 11.57 & 15.12 & 55.27 \\
\hline Population & Persons & Millions & 63.50 & 65.41 & 67.22 & 69.10 & 71.04 & 73.03 & 75.07 & 77.17 & 79.18 \\
\hline Current account balance & U.S. dollars & Billions & -0.34 & -0.23 & -0.35 & -0.11 & -0.40 & -0.74 & -1.39 & -0.87 & -1.49 \\
\hline Current account balance & Percent of GDP & & -4.24 & -2.96 & -4.67 & -1.36 & -4.00 & -6.00 & -9.14 & -4.48 & -5.80 \\
\hline
\end{tabular}


